Special Issue on Longitudinal Methodology, Canadian Studies in Population

Vol. 28(2), 2001, pp. 513-533

\title{
Women's Employment Transitions and Changes in Psychological Distress
}

\author{
Piotr Wilk \\ Department of Sociology \\ University of Western Ontario \\ London, Ontario, Canada
}

\begin{abstract}
The effect of employment on women's psychological wellbeing has become an important issue in sociology of mental health. Although work-for-pay is thought to have an overall positive impact on women's psychological wellbeing, not all women equally experience this positive effect. The objective of this study is to assess the effect of transitions in employment status on changes in psychological distress among women in two types of family setting: lone parent families and married couple families (including common-law unions). Using a framework which combines a longitudinal design with a structural equation modeling multigroup analysis, the current study indicates clearly that employment transitions and employment stability have no uniform effect on the mental health of all mothers. Specifically, transition into employment offers a significant reduction in feelings of distress only among married mothers. Single mothers, in contrast, are found to experience a significant increase in the level of distress when they move out of employment. The results of this study point to some advantages of longitudinal research designs over cross-sectional designs.
\end{abstract}


Empirical Research and Applications - Piotr Wilk

\section{Résumé}

L'effet de l'emploi sur le bien-être psychologique des femmes est devenu une question importante en sociologie de santé mentale. Bien que le travail payé ait un impact positif global sur le bien-être psychologique des femmes, pas toutes les femmes éprouvent également cet effet positif. L'objectif de cette étude est d'évaluer l'effet des transitions dans le statut d'emploi sur des changements de la détresse psychologique parmi des femmes dans deux types de famille: familles à un seul parent et familles à couple mariés (y compris les mariages de fait). En utilisant un cadre qui combine une analyse longitudinale avec une équation structurale modelant plusieurs groupes, l'étude actuelle indique clairement que les transitions d'emploi et la stabilité d'emploi n'ont pas un effet uniforme sur la santé mentale des mères. Spécifiquement, la transition vers l'emploi offre une réduction significative des sentiments de la détresse seulement parmi les mères mariées. Les mères seules, en contre partis, ont une augmentation significative du niveau de la détresse quand elles sortent de l'emploi. Les résultats de cette étude indiquent quelques avantages de la recherche longitudinale.

Key Words: Employment transitions, psychological distress, structural equation model

\section{Introduction}

The effect of employment on women's psychological wellbeing has become an important issue in sociology of mental health. Although work-for-pay is thought to have an overall positive impact on women's psychological wellbeing, not all women experience this effect equally. Family structure, defined as the intersection of marital and parental status, has been found to provide a particularly important context in which paid work is experienced (Ali and Avison, 1997).

The objective of this study is to assess the effect of transitions in employment status on changes in psychological distress among women with children. ${ }^{1}{ }^{1}$ To find out how family structure provides a context in which paid work is experienced, the current study examines women in two types of family setting: lone parent families and married couple families (including common law unions). The effect of employment transitions on change in distress is analyzed separately among single and married mothers, using a framework that combines a longitudinal design with a structural equation modeling multi-group analysis. ${ }^{2}$ The first section of this paper provides a brief review of the literature on the effect of employment on women's psychological well being. The following 
Women's Employment Transitions and Changes in Psychological Distress

section points out some advantages of longitudinal research design, discusses structural equation modeling in this context, and introduces the measurement instruments. The statistical results are then presented, followed by a brief discussion of these results.

\section{Theoretical Framework}

With the growing number of women in the labour force, the effect of employment on women's psychological wellbeing has become an important issue in sociology of mental health. In general, work-for-pay has been found to have a positive influence on women's psychological wellbeing (Barnett and Marshall, 1992; Glass and Fujimoto, 1994). However, not all women experience this positive influence equally. Past research has found that the magnitude of this effect depends, to a large extent, on contextual factors of home environment (Ali and Avison, 1997; Avison, 1995; Menaghan, 1989). Family structure, defined as the intersection of marital and parental status, provides a particularly important context in which paid employment is experienced. Ali and Avison (1997: 346) argue: "[The concept of family structure] is particularly useful in understanding variations among women in the effect of paid work because it can identify the strains and resources faced by women occupying different role constellations and link them to their structural positions in society. In several ways, the responsibilities and available resources of a working mother may be determined more by the intersection of her marital status with her parental status than by either alone."

The literature on women's mental health reveals that paid employment affects differently the psychological wellbeing of married and single mothers who bear primary breadwinning responsibility alone (Ali and Avison, 1997; Avison, 1995; McLanahan and Adams, 1987; Menaghan, 1989). ${ }^{3}$ The "role salience hypothesis," for instance, posits that because of the perceived responsibility of providing for their families, single mothers are expected to benefit more, both psychologically and in financial terms, from working for pay than married mothers (Ali and Avison, 1997; Avison, 1995; Menaghan and Parcel, 1990; Ross, Mirowsky, and Goldsteen, 1990). At the same time, studies indicate that the positive effect of employment on mental health may be counterbalanced by the strain associated with providing care for children (Kessler and McRae, 1982; Lennon and Rosenfield, 1992; Moen, 1989). This attenuation in the positive impact of paid work is expected to be significantly greater among single mothers who are left alone to cope with housework and child-rearing responsibilities than among comparable married mothers (Ali and Avison, 1997; Avison, 1995). That is, single mothers who are the sole providers for their children are expected to benefit less from employment than married mothers. Finally, marriage has been found to be a significant source of available psychological resources (Pearlin and McCall, 1990). As a consequence, married mothers are often better equipped to cope with stress associated with employment. Single mothers on the 
other hand lack this important source of psychological support. As a consequence, they are expected to derive fewer psychological benefits from work-for-pay relative to married mothers (Ali and Avison, 1997).

Based on the above discussion, this paper tests three hypotheses: 1) paid employment has an overall positive impact on women's mental health; however, with different magnitude for single and for married mothers. 2) According to the role salience hypothesis, single mothers are predicted to benefit more from working for pay than married mothers. 3) However, because of the greater strain associated with child-caring responsibilities, as well as due to the unavailability of psychological resources related to marriage, the positive effect of employment is expected to be attenuated more among single than among married mothers.

\section{Research Design}

\section{Cross-sectional Versus Longitudinal Research Design}

Most studies on the relationship between employment status and psychological wellbeing use cross-sectional research designs, despite results indicating that distress is a dynamic process that changes over time. A cross-sectional design allows researchers to compare average distress scores among subjects who are either employed or unemployed at a single time point. However, it does not distinguish whether individuals working for pay at the time of interview have been stably employed or have only recently made a transition into employment. Similarly, the sample of unemployed subjects may include individuals who have been unemployed for a long period of time, as well as individuals who have only recently moved into that category. The longitudinal process-oriented approach addresses this shortcoming. That is, it allows for the examination of the effect of transition and/or stability in employment status on change in distress (Ali and Avison, 1997; Dooley et al., 1994; Lichter and Landry, 1991).

\section{Structural Equation Modeling}

The theoretical model hypothesized in this study will be analysed using structural equation modelling (SEM) techniques with maximum likelihood estimation. SEM is a technique for simultaneously estimating the relationships between observed and latent variables (the measurement model), and among latent variables themselves (the structural model).

SEM has not been used in previous research on the effect of employment transitions on change in psychological wellbeing. Instead, this relationship has been estimated by regression techniques (Ali and Avison, 1997). As a consequence, the empirical results obtained in the current study may not be 
Women's Employment Transitions and Changes in Psychological Distress

easily compared to the previous findings. However, this should not be seen as a limitation of the present research. In fact, SEM seems to be a more appropriate and more powerful technique to address the problem at hand than regression analysis. One of the primary advantages of SEM is that, compared to regression analysis, it allows the researcher to account for and estimate the size of measurement error. ${ }^{4}$ Rogosa (1980) argues that because potentially confounding influences of measurement error are accounted for, the SEM methodology produces more accurate estimates of causal relationships than models assessed by more traditional techniques.

\section{Data}

The data for this study are drawn from a case-comparison longitudinal study of single parent and two-parent families living in London, Ontario, Canada. ${ }^{5}$ The sampling frame was generated from the 1989 London Municipal Assessment File. To ensure adequate representation of the sample across socioeconomic circumstances, a two-stage stratified sampling strategy was used. These procedures resulted in the completion of interviews with a sample of 518 single mothers and 502 married mothers with a response rate of 66.5 percent (Time One). Interviews were conducted face-to-face by fully trained interviewers in people's homes. Only mothers fifteen years of age or older with at least one child under age seventeen were selected to participate in the survey. The second interview was conducted after a period of eighteen months (Time Two). At that time, 472 of the original 518 single mothers and 476 of the 502 married mothers were successfully re-interviewed (a retention rate of 91.1 percent and 94.8 percent, respectively). ${ }^{6}$ To avoid confounding the effect of changes in marital status between waves, 88 mothers whose marital status changed between the first and the second interview were excluded from the analysis. Finally, preliminary analysis indicated that the problem with missing data was not severe; a listwise deletion of eight cases with missing data points resulted in the total loss of less than one percent of the total sample. ${ }^{7}$ Thus, the final sample used in this study consists of 396 single mothers and 450 married mothers.

The parameter estimation method and significance tests in structural equation models operate under a number of assumptions. For that reason, all manifest variables have been checked for any abnormalities and violations of these assumptions. Descriptive statistics for the observed variables are presented in Table 1, including the means, medians, standard deviations, skewness, kurtosis, minimums, and maximums.

Structural equation modelling that uses the maximum likelihood procedure for parameter estimation assumes that the variables are normally distributed (multivariate normality). Although the results of tests for skewness and kurtosis suggest (see Table 1) significant departures from normality for a number of manifest variables, parameter estimates in structural models using the maximum 
Empirical Research and Application -Piotr Wilk

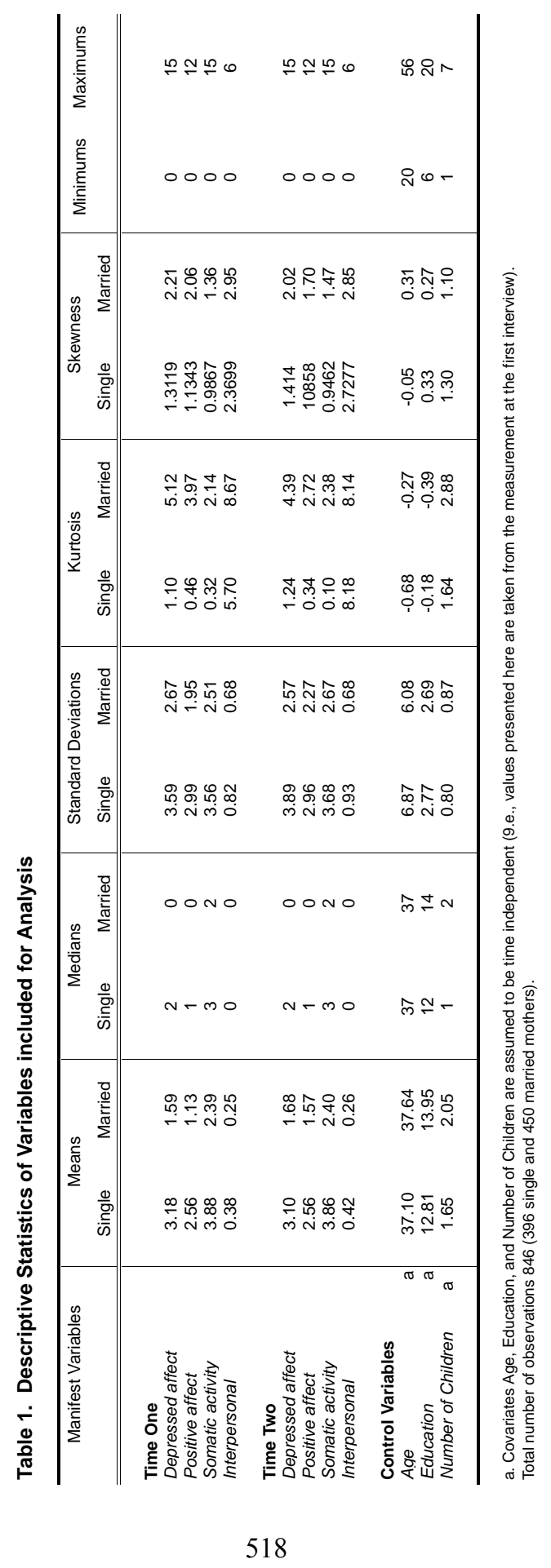


Women's Employment Transitions and Changes in Psychological Distress

likelihood criterion are quite robust against violations of the assumption of a normal distribution (Bollen, 1989). However, to assess the magnitude of a potential bias related to this violation, a test involving the comparison of the maximum likelihood standard errors with bootstrapped estimates of the standard error was performed. An analysis of these values (not shown) revealed that when the bootstrapped estimates of the standard errors were compared to the standard error estimates obtained in the maximum-likelihood model, no substantial differences were observed. Thus, the assumption of a normal distribution was not violated when maximum-likelihood estimation was employed, despite the fact that the distributional assumption was violated in the case of a few variables. The extremely low values of the standard errors of the bootstrapped standard errors support this conclusion.

\section{Measurement}

Employment status. At each interview, the respondents were asked whether they were working for pay or not. Based on this information, it was possible to distinguish mothers who remain in the same employment category over the period of eighteen months ('stayers') from mothers who transfer into a different employment category ('movers'). In the end, four dynamic employment status categories were distinguished: Employed (mothers who were employed at both time points; $\mathrm{N}=525 ; 62.1 \%$ ); Unemployed (mothers who were unemployed at both time points; $\mathrm{N}=179 ; 21.2 \%$ ); Out-movers (mothers who were employed at Time One but were unemployed at Time Two; $\mathrm{N}=63 ; 7.4 \%$ ); and In-movers (mothers who were not employed at Time One but had a job at Time Two; $\mathrm{N}=79 ; 9.3 \%)$.

Marital status. Single mothers were defined as never-married, separated, divorced, or widowed women with at least one child under age 17 ( $\mathrm{N}=396$; $46.8 \%$ ). Married mothers included women who lived with their husband or cohabiting partner with at least one child under age $17(\mathrm{~N}=450 ; 53.2 \%)$.

Psychological distress. The measure of psychological wellbeing is based on the CES-D scale (Center for Epidemiological Studies Depression Scale) (Radloff, 1977), which is one of the most widely used measures of distress. This 20-item instrument was designed to measure an individual's current level of depressive symptoms, with emphasis on depressed mood. Using factor analysis, Radloff classified the items into four types of depressive symptoms: depressed affect (5 items: blues, depressed, lonely, cry, sad); positive affect (4 items: good, hopeful, happy, enjoy); somatic and retarded activity (5 items: bothered, appetite, effort, sleep, get going); and interpersonal ( 2 items: unfriendly, dislike). ${ }^{8}$ For the purpose of this study, a latent construct labeled DISTRESS was derived from the above four linear components (additive sub-scales) of psychological distress: Depressed affect, Positive affect, Somatic activity, and Interpersonal. ${ }^{9} \quad$ This 
Empirical Research and Applications - Piotr Wilk

measurement provides a more concise measure of Radloff's concept of distress than the commonly used 20-item additive scale.

Control variables. To assess the independent impact of employment transitions on change in psychological distress, three socio-demographic controls (age, educational attainment, and number of children) were introduced. Educational attainment is measured through a single indicator (continuous) variable Education. The survey asked respondents to indicate the highest grade of school (or years of college or university) they completed with scores ranging from 1 to 20. Age was measured on a continuous scale in years, ranging from 20 to 56 . Since psychological wellbeing is expected to display a parabolic relationship with age, age was modeled in a quadratic form. Finally, because of non-normal distribution, the continuous variable Number of Children was recoded into three discrete categories: 'One child', 'Two children', and 'Three or more children'.

\section{Measurement Model}

The outline of the hypothesized measurement model for psychological wellbeing is presented in Figure 1 (the two models represent the same measurement at separate times). The model shows the hypothesized relationship between each variable, depicted by rectangles, and the latent construct DISTRESS, which following convention, is represented by large, oval-shaped circles. ${ }^{10}$ Each indicator has an error term associated with it (variables $e 1$ through $e 4$ ), making it explicit that the observed variables are influenced not only by the latent construct but also by measurement errors.

A hypothesized model is considered to fit the data well if there is a close match between an estimated covariance matrix generated by this model and the covariance matrix obtained from the sample data. ${ }^{11}$ When subjected to a confirmatory factor analysis, the hypothesized four-item factor structure resulted in an excellent fit; Time One: construct but also by measurement errors. $\chi^{2}=5.828(\mathrm{df}=2) ; \mathrm{GFI}=.997 ; \mathrm{CFI}=.998 ; \mathrm{IFI}=.998 ; \mathrm{RMSEA}=.048 ;$ and Time Two: $\chi^{2}=4.814(\mathrm{df}=2) ; \mathrm{GFI}=.997 ; \mathrm{CFI}=.998 ; \mathrm{IFI}=.998 ; \mathrm{RMSEA}=.041$. As indicated in Figure 1, all standardized factor loadings were substantial, mostly above .80, giving support for the hypothesized structure of the measurement model.

\section{Stability of Measurement Model}

Before assessing the effect of employment transitions on change in psychological distress, it is important to examine across-time stability of the measurement instrument for the latent construct DISTRESS. To achieve this objective, an across-occasions measurement model was constructed in which the latent variable DISTRESS Time One was hypothesized to cause the respective latent variable, DISTRESS Time Two (see Figure 2). The measurement errors for 
Figure 1: Measurement Model of Psychological Distress

\section{Time One}

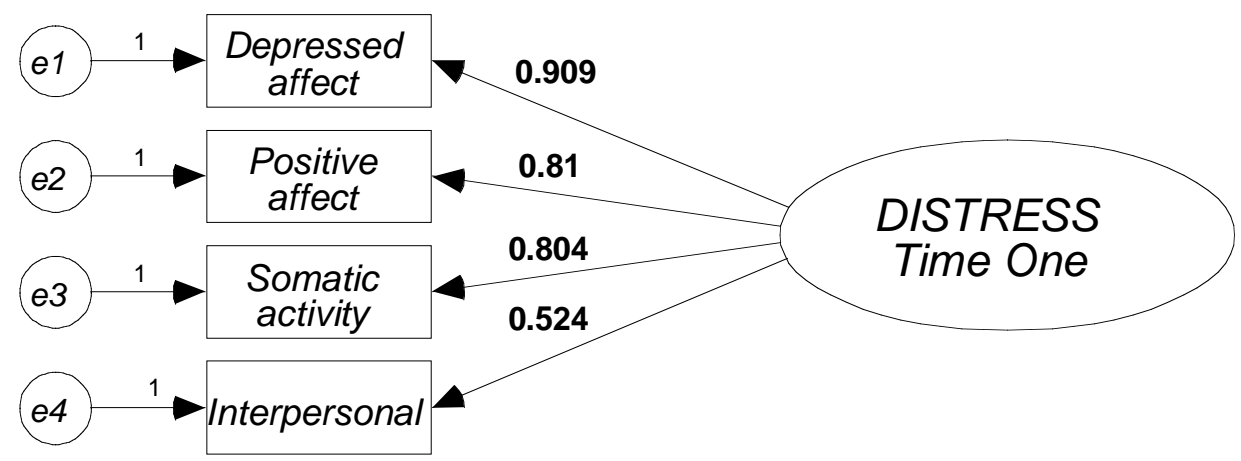

\section{Time Two}

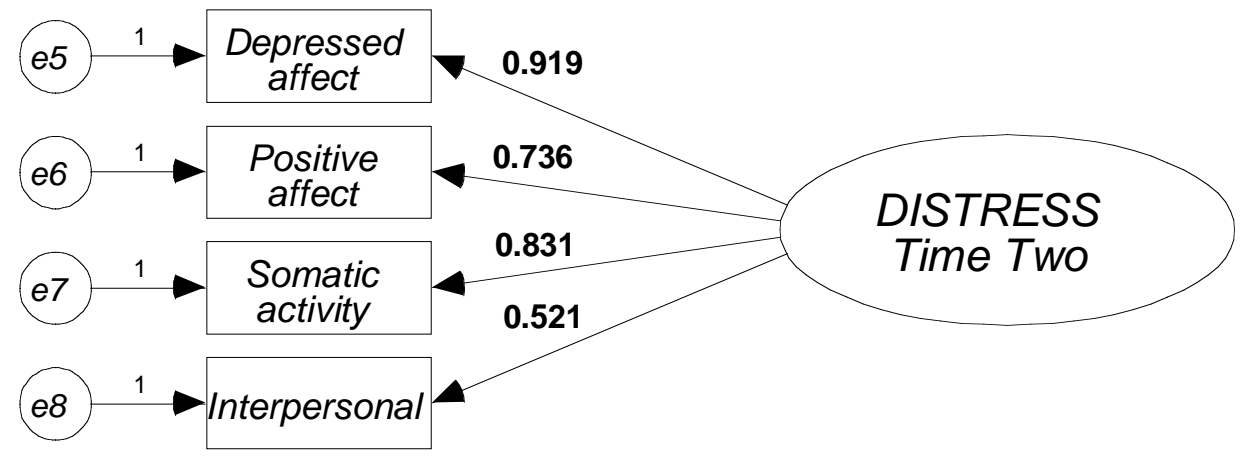


Empirical Research and Application-Piotr Wilk

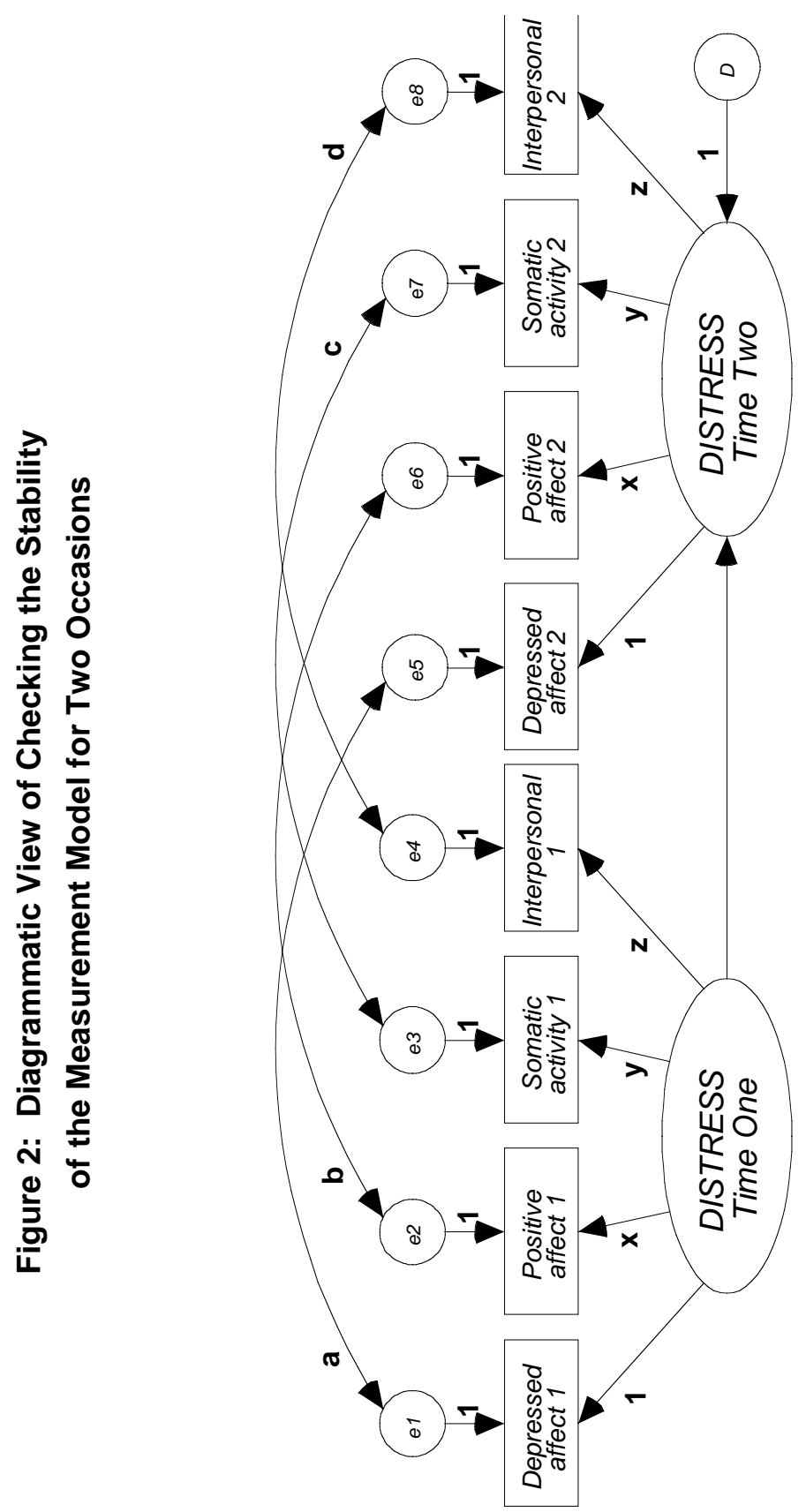


Women's Employment Transitions and Changes in Psychological Distress

the corresponding manifest variables were allowed to covary over occasions (parameters a, b, c, and d). "Empirically, this has been found a common feature of such models and probably arise from the fact that each indicator has some indicator specific variation as well as measurement error"(Ecob, 1987: 142-43). This assumption was confirmed by comparing the fit of the model with the autocorrelated error terms with the more restrictive models where the measurement errors of the manifest variables were independent across occasions. A statistically significant reduction in $\chi^{2}$ of $226.342(\Delta \mathrm{df}=4)$ indicated that the model with correlated error terms fits the data better.

In determining whether the measurement process remains constant over time, the factor loadings of the manifest variables for the corresponding latent variables were fixed to be invariant across time (parameters $\mathrm{x}, \mathrm{y}$, and $\mathrm{z}$ ). The observed difference in the chi-square statistic between the model with unconstrained factor loadings and the model with constrained factor loadings was used to test the validity of this assumption. This restriction produced a statistically non-significant increase in the chi-square $\left(\Delta \chi^{2}=5.933 ; \Delta \mathrm{df}=3\right)$, indicating that the measurement properties of the latent variable DISTRESS were the same on both occasions. ${ }^{12}$

One of the features provided by the SEM software is a set of the modification indices for all parameters that are explicitly or implicitly constrained to zero. These indices estimate the minimum change in the chi-square value for the overall model that is expected to result if a given parameter is added to the model. The modification indices reported for the above measurement model suggest that the model fit would improve significantly if the covariance between the error terms of Interpersonal 1 and Depressive affect 2, as well as covariance between the error terms of Interpersonal 1 and Positive affect 2 were added; the expected improvements in the chi-square units were 10.299 and 9.371, respectively. However, these parameters were not added to the model. While these changes could be justified on statistical grounds, they would distort the structure of the conceptual model that the current study is attempting to evaluate. ${ }^{13}$

\section{Results}

\section{Change in Psychological Distress}

The squared multiple correlation $\left(\mathrm{R}^{2}\right)$ for the latent variable DISTRESS Time Two for the combined sample of married and single mothers was estimated as .30 , suggesting that a substantial portion of mothers experienced changes in the level of distress between the two interviews. When the correlation between DISTRESS Time One and DISTRESS Time Two was assessed separately for 
samples of single and married mothers, the correlation was slightly higher among single than among married mothers; however, the across-group difference was not statistically significant at $p=.05$.

The multiple-group analysis of structural means indicated that the across-time changes in the mean values of the latent variable DISTRESS for single mothers $(\Delta$ Mean $=.078 ; 15$-point scale $)$ and for married mothers $(\Delta$ Mean $=.223 ; 15$-point scale) were not statistically significant $(p=.05)$, implying a within-group stability in the average level of distress during the period of eighteen months between interviews. ${ }^{14}$ An additional test showed that, on both occasions, single mothers were significantly more distressed than married mothers; the observed difference in the mean values of the latent variable DISTRESS was 1.710 at Time One (15-point scale; $p<.001)$ and .581 at Time Two $(p<.01)$.

(Figure 3 about here)

\section{Effect of Employment on Psychological Distress}

The structural equation model was constructed to assess the influence of employment transitions on changes in psychological wellbeing. As given in Figure 3, the latent variable DISTRESS Time One is hypothesized to cause the latent variable DISTRESS Time Two. Figure 3 outlines only the structural part of the model since the measurement model has already been presented in Figure 2. The model includes four indicator (dummy coded) variables representing stability and transitions in employment status (Employed, Unemployed, Outmovers, and In-movers). As mentioned earlier, to estimate the independent effect of transitions in employment on psychological wellbeing, the following control variables were entered into the model: Age, Age square, Education, and two dummy coded variables for number of children: 'Two Children' and 'Three Children'. All the exogenous variables (control variables, the dummy coded variables representing employment status, and the latent variable DISTRESS Time One) were hypothesized to correlate freely among themselves.

The initial analysis was conducted for the combined sample of single and married mothers. The hypothesized SEM model resulted in a good fit: $\chi^{2}=143.231 \quad(\mathrm{df}=66) ; \quad \chi^{2} / \mathrm{df}=2.17 ; \quad \mathrm{GFI}=.979 ; \quad \mathrm{CFI}=.990 ; \quad \mathrm{IFI}=.990 ; \quad$ and RMSEA $=.037$. The model accounted adequately for the observed covariances among the manifest variables. The regression coefficients for the structural part of the model are shown in Table 2, panel 1.

The results of the analysis for the combined sample of single and married mothers reveal that, while controlling for age, educational attainment, and number of children, transition into employment (relative to stable unemployment) produced a statistically significant $(p<.05)$ decrease in psychological distress - a decline of .739 on a 15-point scale. However, 
Women's Employment Transitions and Changes in Psychological Distress

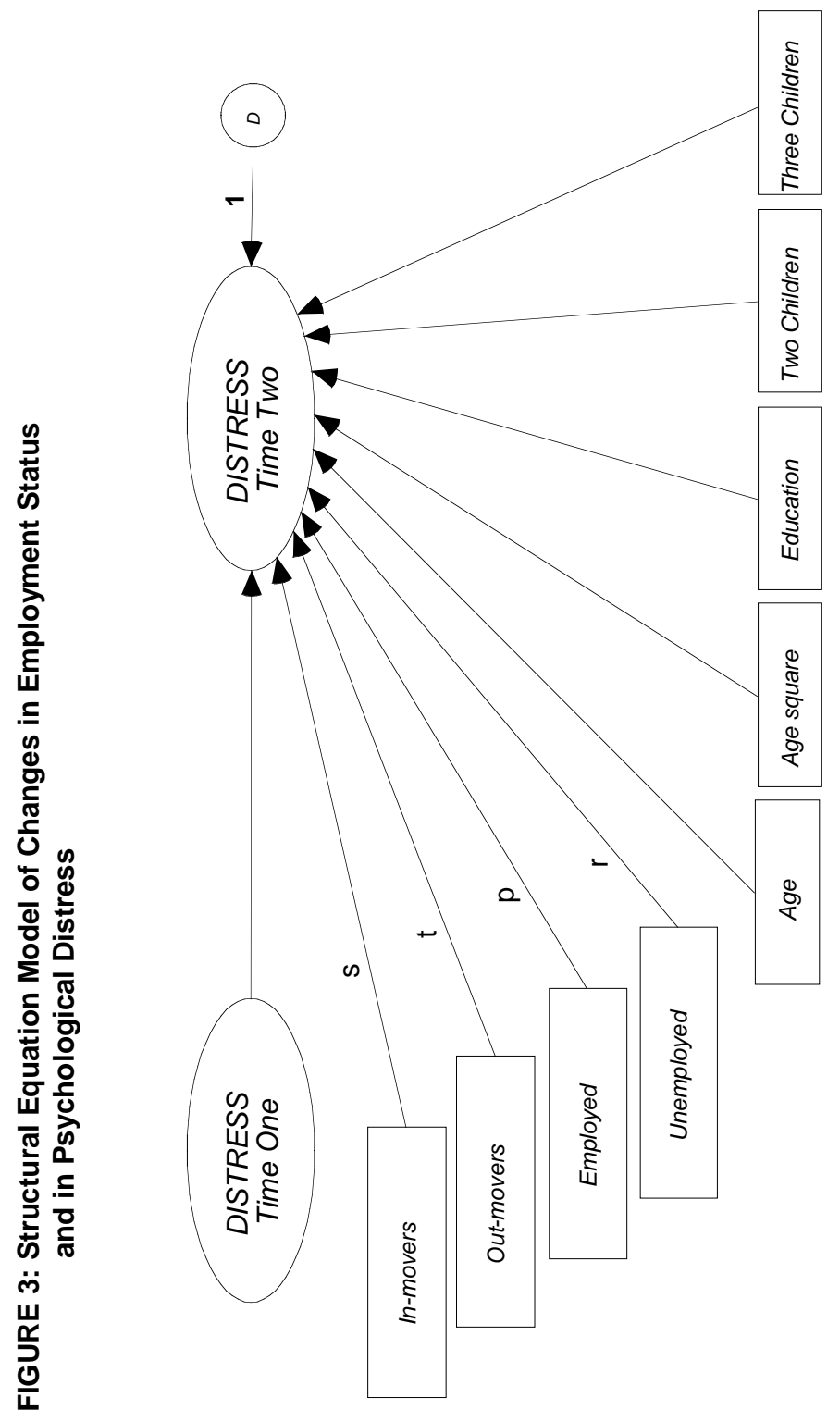


transition out of the labour force (relative to stable employment) did not cause a significant change in the level of distress - an increase of .393 is not statistically significant at $p=.05$. Finally, when compared to the stable unemployed mothers, mothers who participated in the labour force at the time of both interviews experienced, on average, a significantly larger improvement in the area of psychological wellbeing - the reported difference of .674 measured on a 15point scale is statistically significant at $p<.01$.

To examine the contextual role of marital status, a multi-group analysis was conducted in which the influence of marital status (group variable) was partialled out. A multi-group analysis tested the proposition that the above reported overall effect of transitions and stability in employment status on changes in distress is the same among single and among married mothers. The two-wave model was fitted simultaneously within each group. As in the case of the previous one group analysis, the model fit was very good: $\chi^{2}=182.096$ $(\mathrm{df}=99) ; \chi^{2} / \mathrm{df}=1.839 ; \mathrm{GFI}=.968 ; \mathrm{CFI}=.967 ; \mathrm{IFI}=.977 ;$ and $\mathrm{RMSEA}=.032$.

However, the results from the multi-group analysis were inconsistent with the results from the combined model (see Table 2, panels 2 and 3). First, contrary to the results from the one-group model, transition into employment was found to produce a significant $(p<.05)$ decline in the level of distress only among the married but not among the single mothers - an improvement in mental health of .915 on a 15-point scale. Thus, contrary to what was hypothesized, taking a job for pay offered no significant reduction in single mothers' feelings of distress. Second, when compared to stable employed single mothers, single mothers who became unemployed were found to be significantly more distressed at the time of the second interview than at the time of the first interview - a difference of 1.312 on a 15-point scale. This relationship, however, was suppressed in the combined sample analysis. Finally, the previously observed 'positive' effect of stable employment on changes in distress was replicated only among single mothers. That is, compared to stable unemployed single mothers, the stable employed single mothers experienced, on average, a 1.148 decrease in the level of distress over the period of 18 months. ${ }^{15}$

To test whether single and married mothers who went through the same type of employment transition/stability experienced also the same magnitude of change in distress, a series of across-group equity constraints was imposed on path coefficients for the dummy coded variables Employed, Unemployed, In-movers, and Out-movers (parameters $q, r, s$, and $t$ in Figure 3). ${ }^{16}$ The results of this analysis indicated that transition into employment had the same impact on change in distress among single and married mothers $\left(\Delta \chi^{2}=.303\right.$; not significant at .05$).{ }^{17}$ However, the transition out of paid work produced a significantly larger change in the level of distress among single than among married mothers $\left(\Delta \chi^{2}=6.711 ; p<.01\right)$. Similarly, the stable employed single mothers experienced significantly different changes in the level of distress than stable employed married mothers $\left(\Delta \chi^{2}=4.409 ; p<0.5\right)$. 
Women's Employment Transitions and Changes in Psychological Distress

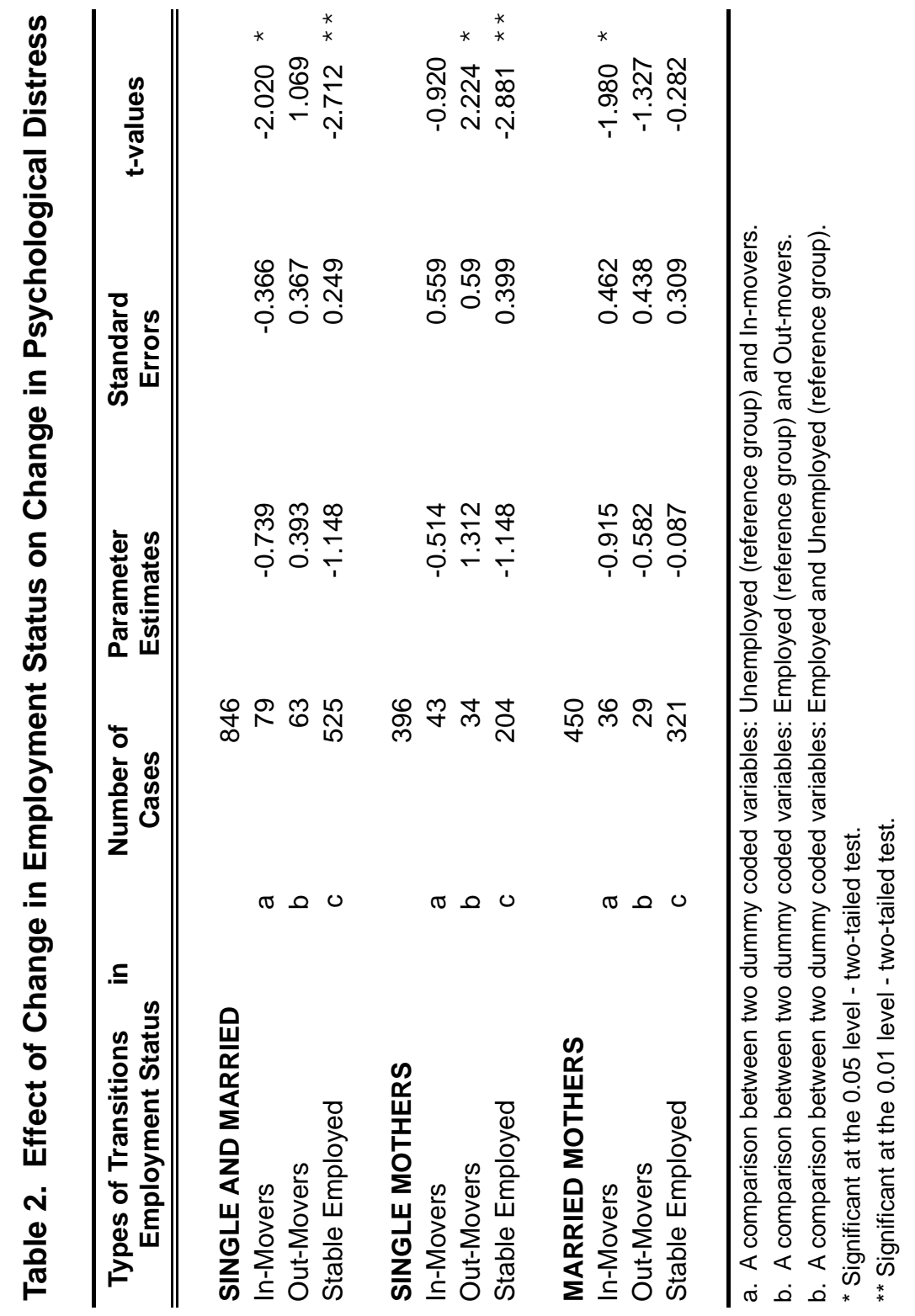


Empirical Research and Applications - Piotr Wilk

\section{Conclusion}

The current study indicates clearly that employment transitions and employment stability have no uniform effect on the mental health of all mothers. That is, family structure, and marital status in particular, provide a context in which paid work is experienced. Transition into employment has been found to offer a significant reduction in feelings of distress only among married mothers. Single mothers, however, experienced a significant increase in the level of distress when they moved out of employment.

The results of this study have some significant implications for further research in the area of women's mental health. First, they point to some advantages of longitudinal research designs over cross-sectional designs. Since cross-sectional analyses are able to assess the effect of employment only from a static point of view, they cannot distinguish whether the level of distress at a given time point is related to women's current employment status or to the recently experienced employment transition (or employment stability). Second, this study demonstrates that policy and program interventions based on cross-sectional analyses may differ from interventions that are recommended by the results of longitudinal studies. For instance, a separate examination of the data collected at each interview (not shown) revealed that single mothers who participated in the labour force had a significantly lower level of psychological distress than single mothers who were not engaged in paid work. This finding would lead one to the conclusion that in order to improve mental health status of single mothers, our resources should be devoted to social programs that encourage unemployed women to find jobs. However, the results of the current longitudinal analysis indicate clearly that transition into paid work on its own does not alleviate psychological distress. Instead, only a long-term stability in employment can produce a desired improvement in single mothers' mental health. Thus, program and policy initiative should place a strong emphasis on helping single mothers in keeping the jobs they already hold. 
Women's Employment Transitions and Changes in Psychological Distress

\section{End Notes:}

1. The conceptual framework adopted in this research is based on Ali and Avison's (1997) model linking transitions in employment status to change in mental health among single and married mothers.

2. The theoretical framework that underlines the current attempt to model the impact of employment transitions on change in women's psychological wellbeing has been simplified to accommodate pedagogical requirements of this paper. That is, the primary objective of this study is to illustrate how the structural equation modeling can be used in longitudinal research.

3. Although the current paper does not assess directly the contextual role of the other component of family structure, namely parental status, a number of studies have indicated that the positive effect of employment is weaker among women with children than among childless women (Aneshensel, Frerichs and Clark, 1981; McLanahan and Adams, 1987).

4. "A major aim of measuring social and behavioral change is to ascertain variables that are closely related to systematic inter- and intraindividual differences in growth or decline. However, a frequent characteristic of data collected in the social sciences is the presence of measurement error in the observed scores. Consequently, the recorded differences between individual test scores at two consecutive measurement occasions, which are the most direct index of change, can exhibit unsatisfactory psychometric properties. In such an empirical context, the error of measurement has a biasing effect upon estimates of correlation coefficients, in particular of the correlation between change and other variables" (Raykov 1993: 353-4).

5. The data were collected by the Center for Health and Wellbeing at the University of Western Ontario (London, Ontario) under the supervision of W.R. Avison. I would like to express my gratitude to Cathy Thorpe for allowing me to use the data.

6. The analysis conducted by Ali and Avison (1997) indicates that there are no significant differences with regard to the distribution of demographic characteristics between respondents interviewed on both occasions and those who were lost to survey.

7. To address the issue of missing data directly, all the proposed models were first estimated under a listwise deletion method and then re-estimated by using the full-information maximum-likelihood estimation criterion offered by the AMOS program (Arbuckle 1997). Results from the full-information models are not reported since they do not differ significantly from those obtained under a listwise deletion method. In addition, six cases, four in the single mothers sample and two in the married mothers sample, were identified as multivariate 
outliers in their own groups and, as a consequence, were excluded from the analysis. To identify multivariate outliers, Mahalanobis distance was used.

8. According to the results of the exploratory factor analysis conducted by Radloff (1977), the remaining four items from the proposed 20-item scale were not correlated with any of the four factors.

9. The four indicators developed here (the so-called "item parcels") of the latent variable DISTRESS (Depressed affect, Positive affect, Somatic activity, and Interpersonal) are composite scores.

10. In the structural equation modeling, all latent variables must have a unit of measurement. However, since they are unobservable, they lack an inherent scale. One way of assigning a scale to a latent variable is to use the metric of one of its indicators, a reference indicator. This can be achieved by constraining a factor loading for one of the indicators to the value of one. Since the manifest variable Depressed affect is used as the reference indicator for DISTRESS, this latent variable is measured on the scale from 1 to 15 .

11. The evaluation of model fit is "one of the most unsettled and difficult issues connected with structural modeling"(Arbuckle 1997: 551). Following Bollen's (1989) recommendation, several criteria were used to evaluate the fit of the model, including the Chi-square $\left(\chi^{2}\right)$, the Chi-square/degrees of freedom ratio $\left(\chi^{2} / \mathrm{df}\right)$, the Cumulative Fit Index (CFI), the Incremental Fit Index (IFI), and the Root Mean Square Error of Approximation (RMSEA). The $\chi^{2}$ is very sensitive to sample size (Jöreskog and Sörbom 1989); thus, in a model with a relatively large sample size, the null hypothesis is expected to be rejected almost all of the time. Because of this limitation, the $\chi^{2}$ was used only to evaluate the relative differences in fit among competing models.

12. An additional test was conducted to test the across-time stability of this measurement instrument within each group (single mothers and married mothers) separately. Results of this test (not shown) indicated that the measurement properties of the constructed latent variable DISTRESS are the same in both groups.

13. In the current study, I followed the recommendations given by the modification indices only when there is some substantive theoretical justification for doing so. In a situation where the modification index for a given parameter is substantially high, a researcher might be tempted to relax the constraint on that parameter. However, modifications should not be introduced unless there exists some strong theoretical justification for doing so (Stevens 1996). 
Women's Employment Transitions and Changes in Psychological Distress

14. In a conventional SEM analysis, it is impossible to estimate the means for all latent variables. However, it is possible to calculate a difference in structural means between two (or more) populations or across time. To estimate such a difference, the mean of one of the latent variables has to be fixed at zero.

15. The estimates of parameter coefficients reported in Table 2 were reproduced when the model was assessed under the full-information estimation criterion. In other words, parameters estimated in the two models did not differ in magnitude and in the level of significance. Thus, the above reported effects of employment transitions on change in distress were not affected by the problem of missing data.

16. To conduct these tests, one of the four dummy coded variables for employment status was removed at a time from the model to serve as a reference group.

17. These tests do not allow for the calculation of the actual across-group difference in experienced level of change in psychological distress.

\section{References:}

Ali, J. and W. R. Avison. 1997. "Employment transitions and psychological distress: The contrasting experiences of single and married mothers," Journal of Health and Social Behaviour 38: 345-362.

Aneshensel, C., R. Frerichs, and V. Clark. 1981. "Family roles and sex differences in depression," Journal of Health and Social Behavior 22: 379-93.

Aneshensel, C. and G. Huba. 1984. An integrative causal model of the antecedents and consequences of depression over one year, in J.R. Greenley (ed.). Research in Community and Mental Health, Vol. 4. Greenwich, CT: JAI Press.

Arbuckle, J. L. 1997. AMOS: User's Guide Version 3.6. Chicago: Small Waters.

Avison, W. R. 1995. "Roles and resources: The effects of family structure and employment on women's psychosocial resources and psychological distress," Research in Community and Mental Health 8: 233-56.

Barnett, R. C. and N. L. Marshall. 1992. "Worker and mother roles, spillover effects, and psychological distress," Women and Health 18: :9-40.

Baer, D. 1997. Latent Variables Structural Equation Models (Course Notes for Sociology 601, Winter 1998). London, Ontario: University of Western Ontario.

Bollen, K. A. (1989). Structural Equations with Latent Variables. New York: Wiley. 
Empirical Research and Applications - Piotr Wilk

Dooley, D., R. Catalano, and G. Wilson. 1994. "Depression and unemployment: Panel findings from the Epidemiologic Catchment Area Study," American Journal of Community Psychology 22: 745-65.

Ecob, R. 1987. Applications of structural equation modeling to longitudinal educational data. In P. Cuttance and R. Ecob. Structural Modeling by Example: Applications in Educational, Sociological, and Behavioural Research. Cambridge:

Cambridge University Press.

Glass, J. and T. Fujimoto. 1994. "Housework, paid work, and depression among husbands and wives," Journal of Health and Social Behavior 35: 179-91.

Jöreskog K.G. and D. Sörbom. 1989. LISREL 7: A Guide to the Program and Applications. Chicago: Statistical Package for Social Sciences.

Kessler, R.C. and J.A. McRae. 1982. "The effect of wives' employment on the mental health of married men and women," American Sociological Review 47: 217-27.

Lennon, M. C. and S. Rosenfield. 1992. "Women and mental health: The interaction of job and family conditions," Journal of Health and Social Behavior 33: 316-27.

Lichter, D. and D. Landry. 1991. "Labor force transitions and underemployment: The stratification of male and female workers," Research in Social Stratification and Mobility 10: 63-87.

McLanahan, S. and J. Adams. 1987. "Parenthood and psychological wellbeing," Annual Review of Sociology 5: 237-57.

Menaghan, E. G. 1989. "Role changes and psychological wellbeing: Variations in effects by gender and role repertoire," Social Forces 67: 693-714.

Menaghan, E. G. and T. L. Parcel. 1990. "Parental employment and family life: Research in the 1980s," Journal of Marriage and the Family 53: 417-31.

Olmstead, R.E., S.M. Guy, P.M. O’Malley and P.M Bentler. 1991. "Longitudinal assessment of the relationship between self-esteem, fatalism, loneliness, and substance use," Journal of Social Behavior and Personality 5:749-770.

Pearlin, L. I. and M. E. McCall. 1990. Occupational stress and marital support: A description of microprocesses, in J. Eckenrode and S. Gore (eds.). Stress between Work and Family. New York: Plenum.

Pearlin, L. I., J. T. Mullan, S. J. Semple, and M. M. Skaff. 1990. "Caregiving and the stress process: An overview of concepts and their measures," The Gerontologist 30: 583-91. 
Women's Employment Transitions and Changes in Psychological Distress

Pearlin, L. I. and C. Schooler. 1978. "The structure of coping," Journal of Health and Social Behavior 49: 2-21.

Plewis, I. 1985. Analysing Change: Measurement and Explanation Using Longitudinal Data. New York: John Wiley.

Radloff, L. S. 1977. "The CES-D scale: A self-reported depression scale for research in the general population," Applied Psychological Measurement 1: 285-401.

Raykov, T. 1993. "On estimating true change interrelationships with other variables," Quality and Quantity 27: 353-70.

Rogosa, D. R. 1980. “Critique of cross-lagged correlations,” Psychological Bulletin 88: 121-132.

Rogosa, D. R. 1979. Causal models in longitudinal research: Rationale, formulation, and interpretation, in J.R. Nesselroade and P.B. Baltes (eds.). 1979. Longitudinal Research in the Study of Behavior and Development. New York: Academic Press.

Rogosa, D. R. and J. Willett. 1983. Demonstrating the reliability of the difference score in the measurement of change," Journal of Educational Measurement 20: 33543.

Rosenberg, M. 1979. Conceiving the Self. New York: Basic Books.

Rosenberg, M., C. Schooler, and C. Schoenbach. 1989. "Self-esteem and adolescent problems: Modeling reciprocal effects," American Sociological Review 54: 1004-18.

Ross, C., J. Mirowsky and K. Goldsteen. 1990. "The impact of the family on health: The decade in review," Journal of Marriage and Family 52: 1059-78.

Scheck, Ch.L., A. J. Kinicki and J. A. Davy. 1995. “A longitudinal study of a multivariate model of the stress process using structural equation modeling," Human Relations 48: 1481-511.

Stevens, J. 1996. Applied Multivariate Statistics for the Social Sciences. Mahwah, N.J.: Lawrence Erlbaum Associates.

Turner, R. J. and S. Noh. 1988. "Physical disability and depression: A longitudinal analysis," Journal of Health and Social Behavior 29: 23-37. 